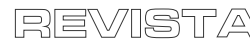 \\ ESMAT
}

\section{DOR DE AMOR OU DANOS DE AMOR? JURISPRUDÊNCIA RENITENTE: O PROBLEMA DO QUANTUM INDEMNIZATÓRIO DA RESPONSABILIZAÇÃO CIVIL NO PLANO DAS RELAÇÕES CONJUGAIS}

LOVE PAIN OR LOVE DAMAGE? RENITENT JURISPRUDENCE: THE PROBLEM OF THE

QUANTUM INDEMNITIES OF CIVIL LIABILITY IN MARITAL RELATIONSHIP

Ludimila de Souza Poirier

Advogada atuante na área de Direito de Família no Brasil e em Portugal; mestranda em Direito: Especialidade em Ciências Jurídico-Forenses na Universidade de Coimbra. E-mail: ludimilapoirier-58745C@adv.oa.pt

\section{RESUMO}

artigo traça algumas considerações acerca do Acórdão do Supremo Tribunal de Justiça de Portugal, proferido em Lisboa, no dia 12 de maio de 20 I6 - Proc.2325/I 2. 3TVLSB.LI.SI. O Acórdão em comento entende que foram violados os deveres de fidelidade e de coabitação, mas, simultaneamente, foram também violados o direito de personalidade, o direito à dignidade pessoal e o direito à saúde. $\bigcirc$ artigo é posto segundo o regime jurídico português e possui breve entendimento da matéria segundo a doutrina brasileira.

PALAVRAS-CHAVE: Casamento. Deveres Conjugais. Responsabilidade Civil. Danos Extrapatrimoniais. Quantum Indemnizatório.

\section{ABSTRACT}

The article outlines some considerations about the Judgment of the Portuguese Supreme Court of justice, ruling issued in Lisbon on 12 May 2016 - Proc.2325 / 12.3TVLSB.LI.SI. The judgment under consideration states that the duties of fidelity and cohabitation were breached, but at the same time the right of personality, the right to personal dignity and the right to health were also violated. The article is presented under the Portuguese legal regime and has a brief understanding of the subject according to Brazilian doctrine.

KEYWORDS: Marriage. Marital Duties. Civil Liability. Extra-Patrimonial Damages. Compensatory Quantum.

\section{INTRODUÇÃO}

O presente trabalho objetiva tecer algumas considerações acerca do Acórdão do Superior Tribunal de Justiça, de 12/5/20 I 6 Proc.2325/I2.3TVLSB.LI.SI . 
Visa perceber em que medida, no momento do divórcio, é cabível a qualquer dos cônjuges pedir indemnização pelos danos não patrimoniais sofridos durante o casamento.

No caso em análise, o casamento durou quinze anos, mas ao longo deste período, e de modo intermitente, o marido abandonava o lar conjugal deixando a esposa $\mathrm{e}$ as duas filhas. A particularidade do caso encontra-se no fato de que, intercalando períodos de ausência e convívio e à medida que igualmente encerrava outros breves relacionamentos, este homem deixava em suspenso o divórcio de fato, e mesmo a relação interpessoal com a autora da Ação, que retomava o papel de mulher e esposa, sempre que o marido voltava à casa. Do convívio com o esposo que alternava esporádicas aparições, surgiu na autora um estado permanente de tristeza, de perda de alegria de viver que culminou em um quadro depressivo. Quinze anos passados, a esposa pretendeu ser indemnizada.

Intenciona-se abordar o art. I.792 do Código Civil, que permite a indemnização e não faz distinção entre os tipos de danos.

De acordo com o Acórdão, entende-se que foram violados os deveres de fidelidade e de coabitação, mas, simultaneamente, foram também violados direitos de personalidade, o direito à dignidade pessoal e o direito à saúde.

O texto do art. $1.792^{\circ}$ do Código Civil, $n^{\circ}$ I, preconiza expressamente o direito à indemnização. A norma admite que é cabível o pedido indemnizatório pelos danos sofridos com a dissolução do casamento e também com os danos sofridos pela violação de direitos durante o casamento.

E quanto à questão do tipo de dano, questiona-se se os danos ressarcíveis são somente os decorrentes de violações ao Direito de personalidade, ou também os danos por conta da violação dos deveres conjugais.

E como pode ser entendida a questão do ilícito endofamiliar?

Desse modo, pretende-se igualmente abordar as questões pertinentes ao quantum indemnizatório, porque afinal, em uma sociedade em que quase tudo tem valor pecuniário, quanto vale a dor de amor?

\section{ATRIBUIÇÃO DE EFEITOS JURÍDICOS AOS AFETOS}

\section{I.I A base principiológica do Direito Matrimonial}

Uma das obras mais levadas aos palcos do mundo inteiro, Romeu e Julieta, encerra a ideia do amor romântico, do casamento e dos arroubos juvenis'. A conhecida

I Daniela Diana, "Romeu e Julieta. Resumo de livros". In < https://www.todamateria.com.br/ romeu-e-julieta> Acesso em: 17/07/2019. 
DOR DE AMOR OU DANOS DE AMOR? JURISPRUDÊNCIA RENITENTE: O PROBLEMA DO QUANTUM INDEMNIZATÓRIO DA RESPONSABILIZAÇÃO CIVIL NO PLANO DAS RELAÇÕES CONJUGAIS

peça, embora marcada pela tragédia, é uma das mais importantes histórias de amor da literatura e é também uma história sobre o destino e os sacrifícios que se fazem em nome do amor².

Stefano Rodotá questiona quanto à existência de compatibilidade entre as palavras "direito" e "amor", ou se estes pertencem a lógicas conflituantes. O autor explica como a lei, desde os tempos passados, tem sido usada como ferramenta para neutralizar o amor em sua presença social, e afirma que na experiência histórica, o direito se apoderou do amor ${ }^{3}$. Para Renata Multedo, "o direito limitou o amor a apenas um perímetro, considerado como o único juridicamente legítimo: o casamento" ${ }^{4}$.

Assim explicado, mesmo a despeito do conteúdo anímico que a ideia do casamento pode portar, é no Código Civil que está assentada a noção jurídica de família e do casamento. $\bigcirc$ art. $1.576^{\circ}$ apresenta como a primeira das relações de família a relação matrimonial. Relação que "em consequência do casamento liga os cônjuges entre si. Uma relação que afeta a condição dos cônjuges de maneira profunda e duradoura, influenciando no seu regime, pode dizer-se, a generalidade das relações jurídicas obrigacionais ou reais de que eles sejam titulares" ${ }^{5}$. $O$ diploma aprovado (Lei n 61, de 31 de outubro, de 2008), em vigor desde $1^{\circ}$ de dezembro de 2008, assenta a conceção do casamento como modo de realização pessoal, "valorizando apenas a dimensão da relação afetiva em detrimento das imposições institucionais, do bem-estar individual em detrimento do bem-estar familiar"6. É o que preconiza a Exposição de Motivos da Lei no 509/X: "Liberdade de escolha e igualdade de direitos e de deveres entre cônjuges, afetividade no centro da relação, plena comunhão de vida, cooperação e apoio mútuo na educação dos filhos, quando os houver, eis os fundamentos do casamento nas nossas sociedades. O casamento é, assim, entendido como um meio de realização pessoal, onde predominam os afetos e, quando estes deixam de existir, o cônjuge infeliz tem

2 Blogue Literário Bertrand. Um amor para vida toda. In < https://bertrandptsomoslivros. blog/2019/02/0 I/um-amor-para-toda-a-vida-romeu-e-julieta>. Acesso em 10/08/2019.

3 Stefano Rodotá, Diritto d'amore, Bari, Laterza, 2015, in <https://www. libreriauniversitaria. it/diritto-amore-rodota-stefano-laterza/libro/9788858121245> e <https:/books.google.pt/ books >. Acesso em: 10/8/2019.

4 "Um contrato de direito público: vigiado pelo Estado; baseado na estabilidade social, na procriação e na educação dos filhos; e portador de uma moral considerada como prevalente, a católica." RenATA VileLA Multedo, Liberdade e família - Limites para a intervenção do Estado nas relações conjugais e parentais, Rio de Janeiro, Editora Processo, 2017, p. 285.

5 Francisco Pereira Coelho e Guilherme de Oliveira, Curso de Direito da Família, Volume I, Coimbra : Coimbra Editora, 2016, p. 32.

6 António José Fialmo, Guia Prático do Divórcio e das Responsabilidades Parentais, 2. ${ }^{a}$ Edição, CEJ, Lisboa, p. 9. 
o direito a pôr termo a essa fonte de infelicidade"7. Assim considerado, tem-se que o novo conceito de casamento está assentado em um princípio de liberdade, e no qual o legislador português assume inequivocamente que ninguém estará obrigado a permanecer casado contra a sua vontade se não houver mais amor. Ou melhor dito que "qualquer cônjuge que considere que o seu casamento já não reúne condições de afetividade, de equilíbrio emocional ou que atente contra a sua dignidade deve poder pôr termo à relação conjugal, mesmo contra a vontade do outro cônjuge" ${ }^{\prime}$. Desse modo, deve bastar, para o encerramento definitivo da vida em comum, a ausência do amor. A falta de vontade de continuar juntos, a falta de afeto, devem ser fundamentos suficientes para que o divórcio possa ser decretado, sem necessidade de mais condições e sem estar na dependência da aceitação do outro cônjuge. Assim, importa que as pessoas estejam felizes no casamento que contraíram, de modo que apenas deve ser mantido enquanto o afeto e o bem-estar persistirem.

abandono do fundamento da culpa no divórcio é convergente com as tendências mais recentes noutros sistemas de direito europeu e foi fortemente influenciado pelos Princípios de Direito da Família Europeu em Matéria de Divórcio e Obrigação de Alimentos entre Ex-Cônjuges elaborados pela Comissão de Direito Europeu da Família?

professor Jean Hauser, ao tratar do tema de amor e liberdade, foi claro ao afirmar que, de modo simples, explica-se que o amor é inicialmente uma demanda individual, mas que, quando compartilhado, deve conter reciprocidade ${ }^{10}$.

Em consonância com o artigo 1.781. ${ }^{\circ}$, alínea d), do Código Civil, eliminado está o regime do divórcio litigioso baseado na violação culposa dos deveres conjugais, e instituído o divórcio sem consentimento, com base em factos objetivos aptos a demonstrar a rutura definitiva do casamento, com a consequente atribuição do direito a qualquer dos cônjuges de requerer o divórcio, independentemente da sua maior ou menor contribuição para a crise matrimonial.

A reforma do direito da família, adotada em 2008, em Portugal, demonstra o desejo de se adaptar à sociedade contemporânea e é resultado direto do movimento observável durante a última década no qual o legislador português prestou particular atenção ao Direito da Família. Ao abandonar o modelo de tipo punitivo que exigia uma avaliação do comportamento dos indivíduos e estabelecer uma falha, o novo

7 Exposição de Motivos da Lei no 509/X, in <https://www.parlamento.pt/ActividadeParlamentar/Paginas/Detalhelniciativa.aspx?BID=33847>, Acesso em: 17/7/2019.

8 António José Fialmo, Guia Prático do Divórcio e das Responsabilidades Parentais, ob. cit., p. 10.

9 Idem.

10 JeAn Hauser, Amour et liberté, la divise contemporaine du couple? La famille en mutation. Archives de Philosophie du Droit. Paris: Dalloz. Tome 57, (2014), p. 73 e ss. 
DOR DE AMOR OU DANOS DE AMOR? JURISPRUDÊNCIA RENITENTE: O PROBLEMA DO QUANTUM INDEMNIZATÓRIO DA RESPONSABILIZAÇÃO CIVIL NO PLANO DAS RELAÇÕES CONJUGAIS

sistema aparenta ter sido projetado no sentido de possibilitar o divórcio e permitir um rompimento definitivo, admitindo independência futura" '.

Em Portugal, é possível o divórcio sem consentimento, no qual é pedido por um dos cônjuges contra o outro com fundamento em determinada causa. Existe também o divórcio por mútuo consentimento que pode ser pedido por ambos os cônjuges, de comum acordo e sem indicação da causa pela qual é pedido ${ }^{12}$.

No divórcio por mútuo consentimento existe o pressuposto de que ambas as partes estejam acordadas quanto à dissolução do casamento. Mas a modalidade de divórcio, sem consentimento, requer o cumprimento dos requisitos constantes nas alíneas do art. $1.781^{\circ}$, quais sejam: "separação de facto por um ano consectivo (al. a), alteração das faculdades mentais do outro cônjuge, quando dure há mais de um ano e, pela sua gravidade, comprometa a possibilidade de vida em comum (al. b); ausência, sem que do ausente haja notícias, por tempo não inferior a um ano (al. c); quaisquer outros factos que, independentemente da culpa dos cônjuges, mostrem a ruptura definitiva do casamento (al. d)"'l3.

O divórcio sem consentimento é requerido com base em causas objetivas bastante amplas ${ }^{14}$, e se considerados "quaisquer outros factos que, independentemente da culpa dos cônjuges, mostrem a ruptura definitiva do casamento"15, cabe aplicar o entendimento da autora Sandra Passinhas, para quem o comportamento processual das partes é relevante como facto comprovativo da rutural ${ }^{16}$.

Em que pese à importância do divórcio, com relação às situações de rutura da vida em comum, importa notar a separação de facto. A doutrina não atribui autonomia à matéria e opta por seguir a orientação legal, na qual a separação surge como uma das causas do pedido de divórcio sem consentimento. Para Jorge Duarte Pinheiro, "a separação de facto tem uma importância que ultrapassa o seu impacto no domínio das causas do divórcio", porque um casal pode viver separado pelos mais

II Paula TÁvora Vítor, Les implicites des techniques de règlemente des comptes dans les coupes séparés: les obligations alimentaires entre ex-époux, in Lex Familiae, Revista de Direito Portuguesa, Centro de Direito da Família, Coimbra Editora, Ano I4 - n. ${ }^{\circ} 27-28$, (2017), p. 137 ess.

12 Francisco Pereira Coello e Guilherme de Oliveira, Curso de Direito da Família, Volume I, Coimbra, Coimbra Editora, 2016, p. 690.

13 Jorge DuArte Pinheiro, O Direito da Família Contemporâneo, $4^{\text {a }}$ Ed., Lisboa, AAFDL Editora, 20I5, p. 522 e ss.

14 Jorge Duarte Pinheiro, O Direito da Família Contemporâneo, ob. cit., p. 522 e ss.

15 Abílıo Neto, Código Civil Anotado, Lisboa, Ediforum Edições Jurídicas, Lisboa, 20ª Ed., 20 18 , p. 1.443 .

16 SANDRA PASSINHAS, O novo paradigma do divórcio em Portugal - Ainda há deveres no casamento? AAW. O Divórcio, Lisboa, Centro de Estudos Judiciários, 2014, p. 34. 
diversos motivos, como a crença no restabelecimento da vida em comum, o desejo de evitar um litígio formal ou até mesmo a simples inércia ${ }^{17}$.

Os autores Francisco Pereira Coelho e Guilherme de Oliveira, em curso de Direito da Família, detalham os princípios concernentes à área da família ${ }^{18}$ e tratam em pormenor os arts. $36^{\circ}, 67^{\circ}, 68^{\circ}$ e $69^{\circ}$ da Constituição que consagram a base principiológica delimitadora da mobilidade do legislador ordinário no Direito da Família. Em atenção aos limites da presente exposição, anotam-se somente alguns dos princípios constitucionais do Direito da Família, em breve referência.

$O$ princípio expresso no art. $36^{\circ} n^{\circ} 1,2^{a}$ parte, do direito à celebração do casamento, por exemplo, determina que a legislação ordinária não pode estabelecer impedimentos que não sejam justificados por interesses públicos fundamentais. De modo a considerar-se inconstitucional qualquer norma que tendesse estabelecer impedimentos com base na raça, na religião ou na nacionalidade dos noivos, ou que, por exemplo, "proibisse ao transexual, na sua nova identidade sexual, contrair casamento, etc"| 9 . Nota-se a importância do "direito de constituir família" atribuído pelo art. $36^{\circ}, n^{\circ} 1,1 .{ }^{a}$ parte, CRP, o art. $67^{\circ}, n^{\circ} 1$, que concede à própria família (considerada "elemento fundamental da sociedade"), um "direito à proteção da sociedade e do Estado", tornandoa, desse modo, objeto de garantia institucional. Observável também é o princípio consagrado no $\mathrm{n}^{\circ} 2$ do art. $36^{\circ}$, que visa, especificamente, subtrair ao direito canónico a regulamentação das matérias aí previstas, atribuindo competência à lei civil para regular os requisitos e os efeitos do casamento e da sua dissolução, independentemente da forma de celebração. $\bigcirc$ art. 36 $6^{\circ}$ n 2 , $2^{\mathrm{a}}$ parte, preconiza o princípio da admissibilidade do divórcio para quaisquer casamentos, visto que igualmente inconstitucional a norma que proibisse o divórcio, em geral ou mesmo só quanto aos casamentos católicos (como acontecia antes do DecretoLei $n^{\circ} 261$, de 1975$)^{20}$.

De acordo com Guilherme de Oliveira, o art. $36^{\circ}, n^{\circ} 3$, consagra o princípio da igualdade dos cônjuges, que é uma aplicação do princípio geral do art. $13^{\circ} \mathrm{com}$ grande interesse prático no que tange ao direito matrimonial, porque o princípio "feriu de inconstitucionalidade as normas do Código Civil que colocavam a mulher casada em situação de desfavor relativamente ao marido, normas que a Reforma de 1977 suprimiu ou adaptou aos novos imperativos constitucionais. (...)"2l.

\footnotetext{
17 "Dois cônjuges podem viver separados de facto até a morte de um deles. Só então a morte dissolverá o casamento." Jorge Duarte Pinheiro, O Direito da Família Contemporâneo, ob. cit., p. 496 e ss.

18 Francisco Pereira Coelmo e Guilherme de Oliveira, Curso de Direito da Família, ob. cit., p. 32.

19 Idem.

20 Francisco Pereira Coelho e Guilherme de Oliveira, Curso de Direito da Família, ob. cit., p. 32.

21 Francisco Pereira Coelho e Guilherme de Olineira, Curso de Direito da Família, ob. cit., p. 148. 
Diante do exposto, ficou confirmada a primazia da liberdade nas questões atinentes ao divórcio. Vale então considerar as lições de Jean Hauser, no sentido de observar se a liberdade se sacrifica mais ou menos na definição que a norma exige. Segundo o entendimento do autor, toda a questão moderna é, talvez, saber quando ocorre esse sacrifício da liberdade. Isto é: finalmente saber quando deixa-se o momento (ou a relação momentânea) pela duração, ou a relação duradoura pela liberdade. Desse ponto de vista, o legislador francês moderno nunca foi capaz de ser muito claro, exceto pelo papel da celebração do casamento ${ }^{22}$. Diversamente, o legislador português pacificou o entendimento do divórcio por mútuo consentimento e "como consequência da eliminação da declaração de culpa no divórcio, excluem-se as sanções patrimoniais acessórias e o direito de indemnização pelos danos causados com a dissolução do casamento, remetendo-se os cônjuges para os tribunais comuns quando esteja em causa a reparação dos danos causados pelo outro cônjuge e nos termos gerais da responsabilidade civil (artigo 1792. ${ }^{\circ}$ do citado Código)"23.

Por mais que se tenha iniciado o presente capítulo invocando Romeu e Julieta, verdadeiramente, o amor não interessa ao Direlto, a liberdade de amar também não, e o "casal" ainda menos.

É a liberdade. Esta é que é uma ideia individual e objetiva. Todo o resto diz respeito a outros ramos da ciência. Mas a definição do que seria um casal, é que diz respeito à lei, e o objetivo perseguido por seus membros controla a qualificação em estrutura. Nem a liberdade per si é suficiente sem considerar-se a duração desejada, ou seja, quando começa um casal e quando este deve terminar ${ }^{24}$.

Para Jorge Duarte Pinheiro, a atual discussão acerca do Direito da Família é fruto de esse ramo ter predominância tanto simbólica como prática, de modo que para o autor "não é o mero prazer intelectual da discussão e da contestação que anima movimentos e críticas. O Direito da Família influi ou pretende influir de modo amplo, na vida de cada indivíduo"25.

Incontestável então o conteúdo evolutivo e polémico do Direito da Famíliaa, permitindo novos debates e alargando entendimentos, no sentido de perceber quais os indivíduos, e quais os direitos, que mesmo dentro das relações conjugais não podem ser negligenciados e que exigem tutela jurídica.

22 JeAn HaUser, Amour et liberté, la divise contemporaine du couple ? La famille en mutation. ob. cit., p. 80.

23 António José Fialmo, Guia Prático do Divórcio e das Responsabilidades Parentais, ob. cit., p. 10.

24 JeAn HAUSER, Amour et liberté, la divise contemporaine du couple ? La famille en mutation. ob. cit., p. 80.

25 Jorge DuARte Pinheiro, O Direito da Família Contemporâneo, $4^{\text {a }}$ Ed., Lisboa, AAFDL Editora, 2015 , p. 16.

26 Idem. 


\section{I.2 Discussões contemporâneas sobre a vida em comum e proteção}

No entendimento de António Menezes Cordeiro, "a família, na sequência de dados psicológicos, sociológicos, morais e culturais em que não cabe insistir, constitui um alargamento primordial das esferas das pessoas"27.

Muito embora não haja distanciamento histórico que permita a observação das diferenças e a evolução do casamento e da vida em comum partilhada, há de se ter certo cuidado ao utilizar as palavras afeto (muito em voga na doutrina brasileira por exemplo) ou amor. Esse cuidado se deve à necessidade de utilizar elemento gramatical que corresponda à natureza do instituto ou que explique o fenômeno jurídico ${ }^{28}$. Nesse sentido, como já dito anteriormente, o autor Jean Hauser afirma que o amor, antes de tudo, torna-se uma noção legal somente depois de um quadro funcional muito reducionista. Como fenômeno individual, ele não interessa ao Direito que só atinge o amor como fonte criadora de uma realidade social. Somente nessa alquimia criativa o amor entra em uma parte variável em relação a outras demandas sociais. Quanto ao casamento clássico, ou tradicional, este continua dominado por uma preocupação com a regulamentação que deve mais à política do que ao amor propriamente dito. ${ }^{29}$

Para Maria Berenice Dias, os vínculos afetivos não são uma prerrogativa da espécie humana, visto que "o acasalamento sempre existiu entre os seres vivos, seja em decorrência do instinto de perpetuação da espécie, seja pela verdadeira aversão à solidão"30. Na visão da doutrinadora, "em lugar de direitos e deveres previstos inocuamente na lei, melhor se o casamento nada mais fosse do que um ninho, em que se estabelecem laços e nós de afeto, servindo de refúgio, proteção e abrigo" 31 . Para a autora, o estabelecimento de normas que assegurem direitos e deveres no casamento representa um tipo de "estatização do afeto": "A esfera privada das relações conjugais tende cada vez mais a repudiar a interferência do poder público, não se podendo deixar de concluir que

\footnotetext{
27 António Menezes Cordeiro, Tratado do Direito Civil Português I, 4a Ed., Coimbra, Almedina Editora, 2012, p. 950.

28 Regina Toledo Damião, Antônio Henriques, Curso de Português Jurídico, ob. cit., p. 183. "A língua portuguesa, tanto ou mais que suas irmãs neolatinas, exige do redator uma criteriosa relação sintagmática (...) porque a mensagem pretendida pelo emissor só logra obter seu desiderato quando, conhecido previamente o pensamento que se busca exprimir há uma distribuição lógica e concatenada das ideias.".

29 JEAN HAUSER, Amour et liberté, la divise contemporaine du couple? La famille en mutation. ob. cit., p. 74.

30 Casamento: nem direitos nem deveres, só afeto, in <http://www.mariaberenice.com.br> Acesso em: 19/7/2019.

31 Idem.
} 
DOR DE AMOR OU DANOS DE AMOR? JURISPRUDÊNCIA RENITENTE: O PROBLEMA DO QUANTUM INDEMNIZATÓRIO DA RESPONSABILIZAÇÃO CIVIL NO PLANO DAS RELAÇÕES CONJUGAIS

está ocorrendo uma verdadeira e injustificável estatização do afeto"32. Maria Berenice Dias considera que a onipotência estatal não está limitada a chancelar o casamento e atribuir responsabilidades ao casal, mas que "interfere na sua vida íntima, impondo deveres e assegurando direitos, como fidelidade recíproca, vida em comum e mútua assistência. A vontade dos nubentes pouco vale"33.

Segundo a autora, é uma "ingerência nitidamente descabida", pela ineficácia jurídica, se considerado o fato de que o descumprimento por si não é capaz de possibilitar o adimplemento via decisão judicial e que na "vigência da sociedade conjugal, o descumprimento desses deveres por um ou ambos os cônjuges em nada afeta a existência, a validade ou a eficácia do casamento" 34 .

Respeitosamente, não se pode conciliar a ideia de que os direitos e deveres contidos na norma são ineficazes. É certo que em evidência estão direitos da personalidade que não podem fugir à proteção Estatal. Também não se perde de vista o quadro de violência doméstica em Portugal, e não ter em conta os deveres e os direitos contidos na norma significaria igualmente dar às costas à intenção do legislador, que visou propriamente cuidar para que o tal "ninho" fosse, antes de tudo, não só lugar de afeto, proteção e refúgio como nas palavras de Maria Berenice Dias, mas um lugar seguro. E segurança na aceção jurídica do termo, sem eufemismo, e sem utilização no sentido alegórico; isso porque se deve ter em conta, com o escopo a análise do acórdão, especificamente o dever de coabitação e quais os elementos que caracterizam a violência conjugal.

Francisco Pereira Coelho e Guilherme de Oliveira apresentam a melhor doutrina no entendimento de que "coabitar" implica comunhão de vida, no sentido de partilha de habitação, mesa e, sobretudo, leito. Atribuindo ao verbo "coabitar" um sentido próprio e mais amplo no direito matrimonial.

Para os autores, a comunhão de leito vai na esteira de entendimento que "o casamento obriga os cônjuges ao chamado 'débito conjugal'. Já vimos que o casamento implica uma limitação lícita do direito à liberdade sexual, no duplo sentido de que a pessoa casada fica obrigada a ter relações sexuais com o seu cônjuge e a não ter essas relações com terceiros" 35 .

Jorge Duarte Pinheiro afirma que na língua portuguesa, coabitação significa "prática habitual de actos sexuais com outra pessoa"36.

Contrariamente à doutrina portuguesa, Maria Berenice Dias entende que " não há como afirmar que tenha o Estado imposto a obrigação de o casal manter relações

\footnotetext{
32 Estatização do afeto, in <http://www.mariaberenice.com.br> Acesso em: 19/7/2019.

33 Idem.

34 Ibidem.

35 Francisco Pereira Coelmo e Guilherme de Olineira, Curso de Direito da Família, ob. cit., p. 4l 3.

36 Jorge Duarte Pinheiro, O Direito da Família Contemporâneo, ob. cit., p. 382.
} 
sexuais". Defende a autora que não é o exercício da sexualidade que mantém o casamento, e que a recusa do contato corporal não gera a possibilidade de ocorrência de dano moral. Igualmente a abstinência sexual não dá azo à indemnização. Para Maria Berenice Dias, é "desarrazoado e desmedido pretender que a 'ausência de contato físico de natureza sexual' seja reconhecida como inadimplemento de dever conjugal" 37.

Mais uma vez, o entendimento do presente trabalho aponta no sentido oposto do afirmado pela autora. A frustração das expectativas sexuais de qualquer dos cônjuges deve também ser considerada sob os aspetos da violência conjugal, se utilizada no contexto de recusa injustificada ou punitiva. $\bigcirc$ acórdão, que dá base ao presente trabalho, descreve, dentre outros fatos, a ausência reiterada do cônjuge varão que retornava ao lar conjugal nos intervalos dos relacionamentos que mantinha em paralelo. $\bigcirc$ réu não intencionava pôr fim ao casamento com a autora da ação, nem deixava de com esta coabitar, quando retornava à casa, passando a assumir o papel marital. Desse comportamento decorreu o adoecimento da mulher, e o Acórdão deveria ter levado em conta as questões conceptuais acerca da violência doméstica e seus aspetos psicológicos.

○studo publicado em 2016 pelo Centro de Estudos Judiciários, em pesquisa multidisciplinar, apresentou que, ao tratar da violência, "estaremos a falar de qualquer forma de uso intencional da força, coação ou intimidação contra terceiro ou toda a forma de ação intencional que, de algum modo, lese os direitos e necessidades dessa pessoa" 38 .

No senso comum, a violência doméstica é largamente compreendida tão somente no aspeto da violência física. Entretanto, a violência contra a mulher inclui também violência sexual e psicológica. E não há distinção caso a violência ocorra na esfera privada, no "ninho" desejado por Maria Berenice Dias, ou seja, dentro da família ou unidade doméstica ou em qualquer outra relação interpessoal em que o agressor conviva ou tenha convivido "no mesmo domicílio que a mulher vitimizada, estando ligados por laços de consanguinidade ou de convivência"39.

Vale afirmar que as relações de conjugalidade, para além de íntimas, são complexas. As interações entre companheiros estão envolvidas por um forte componente emocional e sexual. Não se pode negar o impacto e as consequências traumáticas na vítima de violência doméstica, mesmo se esta não deixa marca aparente na pele. $\bigcirc$ aspeto psicológico deve ser visto com o mesmo rigor.

\footnotetext{
37 Casamento ou terrorismo sexual, in <http://www.mariaberenice.com.br > Acesso em 19/07/2019.

38 Violência Doméstica - Implicações sociológicas, psicológicas e jurídicas do fenómeno - Manual Pluridisciplinar, Caderno Especial, Centro de Estudos Judiciários, Lisboa, (2016), p. I 8 e ss.

39 Violência Doméstica - Implicações sociológicas, psicológicas e jurídicas do fenómeno, ob. cit., p. 18 e ss.
} 
As transformações ocorridas nas últimas três décadas levaram os Estados Europeus a considerar a necessidade de uma revisão nos modelos judiciais vigentes. Observa-se o aparecimento de iniciativas da União Europeia, especificamente do Conselho da Europa, pela promoção da revisão e universalização dos sistemas judiciais no que tange à proteção das vítimas de crime. Fundado nesse objetivo, surge a Recomendação $n^{\circ}$ R (85) I I do Conselho da Europa. Este documento é constituído por um conjunto de linhas de orientação que visam ao melhoramento da administração da justiça sob o ponto de vista da vítima. Especificamente, a Recomendação $n^{\circ} \mathrm{R}(85)$ I I pode ser dividida em três vertentes, quais sejam: informação dada à vítima; compensação do ofensor ou do Estado; tratamento e proteção da vítima pela Justiça $a^{40}$.

Destaca-se, para o presente trabalho, a "compensação do ofensor ou do Estado". Isso por ter em atenção às questões simbólicas: "o sistema judicial não só tem que ser mais eficiente no modo como lida com a violência doméstica, como deve adotar uma estratégia que demonstre à opinião pública a sua preocupação com as vítimas, com a justiça e adequação dos procedimentos, com a punição e regeneração dos criminosos"41.

A interpretação do acórdão em comento é que este deixou de ater-se à necessidade de demonstrar à opinião pública uma real preocupação com a vítima. Todavia, o Superior Tribunal de Justiça não considerou ser o caso de violência doméstica ou violência conjugal, contrariando, assim, uma lógica de proteção que preside todo o Direito da Família, na compreensão de Jorge Duarte Pinheiro: "tutela de um cônjuge perante o outro, contra a desigualdade e a violência na constância do matrimónio"42.

Mesmo que admitidas as questões relativas à liberdade individual e tendo em conta que o réu, no acórdão em comento, valeu-se da liberdade de agir, para Jorge Duarte Pinheiro é admissível plenamente o exercício da liberdade individual, desde que feito de forma responsável e não ameace injustificadamente a coesão familiar ${ }^{43}$. Assim, mesmo abrigados pelo casamento, "aos direitos conjugais aplica-se a garantia comum. A infracção por um cônjuge de direitos individuais, patrimoniais ou pessoais, do outro, que se inscreve numa violação do dever de respeito, é susceptível de determinar responsabilidade civil e criminal nos termos gerais" 4 .

Para Jorge Duarte Pinheiro, nos termos dos arts. $483^{\circ}$ e seguintes, a violação dos deveres conjugais, como os de fidelidade e coabitação, pode acarretar responsabilização civil sob o regramento geral, considerando que a responsabilidade civil é

\footnotetext{
40 Indemnização das vítimas de crimes, in <https://e-justice.europa.eu/home.do?plang=pt\&action=home $>$, Acesso em: 19/7/2019.

${ }^{4}$ Violência Doméstica - Implicações sociológicas, psicológicas e jurídicas do fenómeno - Manual Pluridisciplinar, ob. cit., p. 18 e ss.

42 Jorge Duarte Pinheiro, O Direito da Família Contemporâneo, ob. cit., p. 60.

43 Idem.

44 Jorge Duarte Pinheiro, O Direito da Família Contemporâneo, ob. cit., p. 394.
} 
um instrumento de proteção de todos os direitos subjetivos e, portanto, a violação de um dever conjugal, predominantemente pessoal, pode satisfazer os requisitos da obrigação de indemnizar5.

\section{A RESPONSABILIDADE CIVIL NO DIREITO DE FAMÍLIA}

\section{I O ato ilícito dentro das relações familiares}

São preciosas as lições de Antunes Varela ao tratar das Obrigações em Geral, porque determinam que "as principais diferenças entre as obrigações e as relações de família provém essencialmente do facto de estas se integrarem numa instituição social (família), cujos fins exercem uma vincada influência no seu regime jurídico"46. Para o autor, relativamente aos deveres de carácter pessoal, como, por exemplo, as relações pessoais entre os cônjuges, não podem ser objeto de qualquer relação obrigacional extra círculo de pessoas ligadas pelo respetivo vínculo familiar ${ }^{47}$. Nesse contexto a violação dos deveres pessoais familiares não incide uma simples obrigação de indemnizar a outra parte, à exceção da violação de certos deveres conjugais, cujos interesses lesados são mais amplos ${ }^{48}$.

Sucintamente é possível definir a responsabilidade civil na figura jurídica que ocorre quando uma pessoa deve reparar um dano sofrido por outra, já que a lei faz surgir uma obrigação em que o responsável é devedor, e o lesado credor. Importa dizer que é uma obrigação que nasce diretamente da lei, e não da vontade das partes ${ }^{49}$. A verificação de um dano ou prejuízo é requisito para a existência de responsabilidade civil, e que "apenas em função do dano o instituto realiza a sua finalidade essencialmente reparadora ou reintegrativa" ${ }^{50}$. Exige-se igualmente que haja ligação entre o facto e o dano, no sentido de atender ao que dispõe o n I do art. $483^{\circ}$ do Código Civil, já que não cabe "ressarcir todos e quaisquer danos que sobrevenham do facto ilícito, mas tão-só os que ele tenha na realidade ocasionado." Desse modo, o nexo de causalidade tem papel duplo: na qualidade de pressuposto da responsabilidade civil e de medida da obrigação de indemnizar! .

\footnotetext{
45 Idem, p. 395.

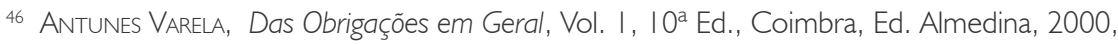
p. 198 e ss.

47 Idem.

48 Ibidem.

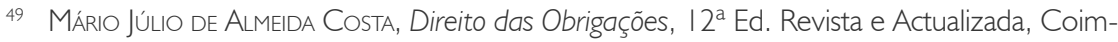
bra : Almedina Editora, 2016, p. 517 e ss.

50 Idem.

51 Mário Júlıo de Almeida Costa, Direito das Obrigações, ob. cit., p. 605. 
Para Rodrigo da Cunha Pereira, o sistema brasileiro, nas relações conjugais, é o princípio da responsabilidade, o motivador pela compreensão e eliminação da discussão da culpa pelo fim do casamento, já que "o discurso da culpa foi substituído pelo da responsabilidade" 52 .

Considerando as questões afeitas às relações íntimas e relacionamentos amorosos em geral, para o doutrinador "quem entra em uma relação amorosa deve assumir os riscos da dor", mas que é possível, em outros tipos de lesões, o prejudicado abrigar-se na esfera do Direito Penal ou do Direito Civil, para buscar a reparação. Todavia ao Estado não interessam os motivos intrínsecos da dissolução do casal ${ }^{53}$.

Contudo, é certo que assiste razão à Bruna Barbiere Waquim quando afirma que "na busca pela felicidade, pela realização pessoal, cada membro da família está sujeito a regras éticas e legais mínimas, a fim de que nesse processo de busca não viole a dignidade e a própria felicidade de seus pares". De acordo com a autora, os danos sofridos pelos cônjuges, no seio da relação conjugal, têm sido convencionalmente chamados de "danos de amor" 54 .

Esses chamados "danos de amor" podem ser compreendidos como, dentre outros, lesão ao património imaterial de um dos membros da relação afetiva pelo seu par, ou, ainda, a quebra da expectativa de compromisso, e como "a frustração injustificada de uma comunhão de vida". A autora segue no entendimento de que, embora os cônjuges tenham a liberdade de escolher a melhor maneira de conduzir a sua vida, "essa liberdade deve ser exercida em solidariedade, observando-se a ética das relações conjugais" 55 .

Não é o caso de permitir uma espécie de monetarização do amor e das relações afetivas, mas, antes de tudo, certo cuidado para evitar que um dos pares, agindo em abuso de direito ou flagrante quebra de confiança ou expectativas por si geradas, "dê azo à violação da dignidade de seu consorte", e tendo em vista que qualquer ação preventiva não seria possível, nada mais certo do que permitir que a dignidade violada seja reparada ${ }^{56}$.

No contexto italiano, verifica-se a figura originada em sede de construção doutrinária e jurisprudencial, a partir do nome altamente sintomático, chamado de ilícito endofamiliar ${ }^{57}$.

52 Rodrigo da Cunha Pereira, Princípios fundamentais norteadores do direito de família, $3^{\mathrm{a}}$ ed. São Paulo, Editora Saraiva, 2016, p. 248 e ss.

53 Idem.

${ }^{54}$ BRUNA BARBIERI WAQUIM, Universos paralelos e danos de amor: balizas para a responsabilidade civil no âmbito das relações simultâneas conjugais, in Revista Brasileira de Direito das Famílias e Sucessões. A. 13, nº 23 (ago./set. 201 I), p. 65-83.

55 Idem.

56 Ibidem.

57 Os textos em língua estrangeira foram por mim livremente traduzidos. E a expressão "endofamiliar", informo não ter encontrado correlativo no léxico português, utilizando-se aqui a expressão, na qualidade de neologismo. 
Para a doutrina italiana, esta é considerada uma subcategoria do crime comum da matriz aquiliana, que tem suas próprias origens definidoras e sua própria razão de ser na circunstância particular de que a responsabilidade extracontratual encontra sua gênese aqui dentro das paredes domésticas, em que "vítima" e "carrasco" fazem parte do mesmo núcleo (não necessariamente fundado no casamento) e o fracasso do relacionamento é muitas vezes acompanhado de uma ofensa contra os valores inalienáveis do indivíduo; isto é, aqueles valores, como a integridade moral e física da pessoa, que existem antes de toda formação social. São os bens que devem sempre ser salvaguardados em sua totalidade, recebendo proteção da Carta Magna antes e independentemente da inserção do indivíduo em qualquer contexto social ${ }^{58}$.

Mas segundo os autores Giuseppe Cassano e Giacomo Oberto, questiona-se quanto à indemnização, se esta pode ser diferenciada de acordo com o contexto em que ela toma forma. Estritamente na lógica e no respeito do senso comum de equidade, a resposta deve ser negativa, pois uma efetiva proteção jurisdicional deve ser independente da área em que o direito amadurece, bem como do sujeito responsável. Para os autores, tais questões são de grande relevância, pois envolvem aspetos éticos contra os quais as respostas não podem ser únicas e definitivas. No entanto, para os doutrinadores, em relevo está o objetivo legítimo, para todo operador jurídico, de buscar tratamento igualitário como expressão de uma justiça que sanciona as prevaricações de qualquer direção de onde elas vêm e em qualquer ambiente em que elas apareçam; então, não conceder-se um direito em nome de um interesse superior (muitas vezes não esclarecido em seu conteúdo) resulta em sua negação na raiz ${ }^{59}$.

\footnotetext{
58 "L'illecito endofamiliare: le premesse. Si è venuta in tal modo elaborando una figura di derivazione dottrinale e giurisprudenziale dall'assai sintomatico nome, l'illecito endofamiliare. Questo è considerato una sottocategoria dell'illecito ordinario di matrice aquiliana che affonda le proprie origini definitorie e la propria ragion d'essere nella peculiare circostanza che la responsabilità extracontrattuale trova qui la sua genesi all'interno delle mura domestiche, ove "vittima" e "carnefice" fanno parte del medesimo nucleo (non necessariamente fondato sul matrimonio) ed ove al fallimento del rapporto non di rado si accompagna l'offesa ai valori irrinunciabili del singolo; ossia a quei valori, quali integrità morale e fisica della persona, che preesistono ad ogni formazione sociale. Si tratta dei beni che vano sempre e comunque salvaguardati nella loro interezza, ricevendo essi protezione dalla Carta dei diritti prima ed a prescindere dall'inserimento dell'individuo in qualsiasi contesto sociale." Giuseppe Cassano, Giacomo Oberto, (et al.), ob. cit., p. 4 e ss.

59 "Il doveroso obbiettivo, per ogni operatore giuridico, della ricerca del trattamento paritario come espressione di una giustizia che sanziona le prevaricazioni da qualunque direzione provengano ed in qualsiasi ambiente si manifestino; quindi, che non concedersi un diritto in nome di un c. d. interesse superiore (spesso non chiarito nei suoi contenuti) si risolve nella sue negazione alla radice", Giuseppe Cassano, Giacomo Oberto, (et al.) - La famiglia in crisi: invalidità, separazione e divorzio dopo le riforme, come si quantificano i profili patrimoniali, quali le conseguenze personali e le relative tutele, Milano, Wolters Kluwer: CEDAM, 2016, p. I e ss.
} 
DOR DE AMOR OU DANOS DE AMOR? JURISPRUDÊNCIA RENITENTE: O PROBLEMA DO QUANTUM INDEMNIZATÓRIO DA RESPONSABILIZAÇÃO CIVIL NO PLANO DAS RELAÇÕES CONJUGAIS

\subsection{A evolução sócio-jurídica e o Direito à Dignidade}

Gomes Canotilho traça um importante aspeto sobre a dignidade, quando afirma que há o expresso reconhecimento da dignidade da pessoa humana como núcleo essencial da República Portuguesa $a^{60}$.

Assim, a consagração do princípio da dignidade da pessoa humana, que tem como um de seus pilares a proteção da liberdade individual, "remete à autonomia existencial, vista como a possibilidade que cada indivíduo tem de construir seu projeto de vida"6l.

Com base nessa ideia, e no facto de as relações conjugais gozarem da possibilidade de maior liberdade de escolhas, para a doutrina brasileira, concretiza-se a opção pela estrutura familiar que melhor convém a cada individuo, sendo assim, ganha importância e relevo o debate acerca de menor regulação estatal sobre as relações conjugais ${ }^{62}$.

Em que pese à ideia de que existem setores da vida privada que por certo devem estar fora do alcance e interesse Estatal, e ainda que o conceito atual de liberdade tenha sido remodelado e ampliado, é preciso "reconhecer a instrumentalidade do papel desempenhado pela autonomia privada, condicionado aos ditames constitucionais"63.

Para Renata Vilela Multedo, acerca da conjugalidade como relação essencialmente volitiva, a família só existirá enquanto representar a vontade dos cônjuges, e daí não caber ao Estado restrição alguma quanto à sua constituição ou dissoluçãa, já que "a descoberta do caminho de realização de seu projeto de vida pertence, de forma exclusiva, ao casal"64.

$\mathrm{Na}$ esteira desse entendimento, a autora defende uma revisão crítica dos deveres conjugais, no que afirma que "mostra-se necessário o questionamento acerca do cabimento e dos limites da atuação estatal no âmbito da vida íntima das relações conjugais por meio da imposição de direitos e deveres recíprocos" 65 .

A autora cita, por exemplo, que o dever de vida em comum, no domićílo conjugal, ou seja, o dever de coabitação, "não se coaduna com a liberdade dos cônjuges em determinarem a possibilidade e a conveniência de viverem em domicílios separados"66.

60 J.J. Gomes Canotilho, Direito Constitucional e a Teoria da Constituição, $7^{\mathrm{a}}$ Ed, Coimbra, Editora Almedina, 2003, p. 250.

${ }_{61}$ Renata Vilela Multedo - Liberdade e família - Limites para a intervenção do Estado nas relações conjugais e parentais, Rio de Janeiro, Editora Processo, 2017, p. 39 e ss.

62 Idem.

63 Ibidem.

${ }^{64}$ Renata Vilela Multedo, Liberdade e família - Limites para a intervenção do Estado nas relações conjugais e parentais, ob. cit., p. 196 e ss.

65 RenATA VILELA Multedo, Liberdade e família - Limites para a intervenção do Estado nas relações conjugais e parentais, ob. cit., p. 227.

66 Idem, p. 231. 
$\bigcirc$ presente trabalho tende a discordar diametralmente do afirmado. Isso tendo em vista a parte geral do Código Civil Português, na qual a autonomia privada não é tida como absoluta; além das questões relativas à segurança social "concretizada na protecção dos mais fracos"67. Por fim, o fato de que o dever de coabitação pode também ser entendido como convivência de acordo com o que prescreve Jorge Duarte Pinheiro, para quem "essa ideia de convivência está subjacente ao art. 1673: a adopção de uma residência da família é imposta como regra para que a vida quotidiana do casal aí se desenrole"68.

No regime jurídico português, o Direito da Família "pugna pelo equilíbrio entre integração e independência" e é presidido pela lógica de proteção que permeia todo o sistema ${ }^{69}$.

De qualquer modo, há o entendimento de que a noção de responsabilidade civil, antes de se referir a indemnizações e reparações, "deve ser entendida como um mecanismo de proteção à integridade física, moral e psicológica dos seres humanos"70. $\bigcirc$ presente trabalho concorda integralmente com essa ideia, porque cada caso concreto demandará uma observação criteriosa dos limites para a aplicação da responsabilidade civil.

\subsection{O Acórdão do Superior Tribunal de Justiça, de 12/5/2016 (Proc. 2.325/I2.3TVLSB.LI.SI)}

O Acórdão do Superior Tribunal de Justiça, de 12 de maio de 2016, relator Tomé Gomes - 2.325//2.3TVLSB.LI.SI ${ }^{71}$, gira em torno de saber em que medida, no momento do divórcio, pode um dos cônjuges pedir indemnização pelos danos não patrimoniais sofridos ao longo do casamento.

$\bigcirc$ casal permaneceu casado durante quinze anos. Como já explicado, o cônjuge varão abandonou a casa, a mulher e duas filhas, mas, de vez em quando, voltava ao lar, à medida que mantinha outros relacionamentos simultâneos intermitentes.

O comportamento do réu causou para a autora uma tristeza permanente, uma perda de alegria de viver, que culminou em um estado depressivo e pelos danos descritos, esta pretendeu ser indemnizada.

\footnotetext{
67 Heinrich Ewald Hörster, A Parte Geral do Código Civil Português, Teoria Geral Do Direito Civil, Coimbra, Editora Almedina, 2007, p. 104.

68 Jorge Duarte Pinheiro, O Direito da Família Contemporâneo, ob. cit., p. 380.

69 Idem, p. 60.

70 BRUNA BARBIERI WAQUim, Universos paralelos e danos de amor: balizas para a responsabilidade civil no âmbito das relações simultâneas conjugais, ob. cit., p. 82.

71 Acórdão Acórdão do STJ de 12 de maio de 2016 Relator Tomé Gomes - 2325/I2.3TVLSB. LI.SI, in <http://www.dgsi.pt/jstj.nsf/954f0ce6ad9dd8b980256b5f003fa8l4/c56c09el3e9d3e7e80257fb l004efld5? OpenDocument>, Acesso em: 19/7/2019. 
DOR DE AMOR OU DANOS DE AMOR? JURISPRUDÊNCIA RENITENTE: O PROBLEMA DO QUANTUM INDEMNIZATÓRIO DA RESPONSABILIZAÇÃO CIVIL NO PLANO DAS RELAÇÕES CONJUGAIS

A autora da ação requereu como indemnização o valor de $€ 100.000,00$ (cem mil euros), e o Tribunal de I Instância atribuiu em sentença uma indemnização no valor de $€ 33.000$ (trinta e três mil euros).

O Tribunal da Relação entendeu que não seria o caso de indemnizar, visto que, na altura, a Autora por não ter pedido o divórcio, estaria a renunciar à pretensão indemnizatória. $\bigcirc$ Tribunal da Relação tendeu igualmente pela não gravidade dos danos, não merecendo a tutela do Direito e, apesar de o $1.792^{\circ}$ do Código Civil referir à indemnização pelos danos sofridos pelo cônjuge, o Tribunal considerou que o artigo deve ser interpretado sistematicamente e, uma vez bem interpretado, esse Direito não dá lugar a indemnização, a não ser por danos aos direitos adquiridos anteriormente pelas pessoas, como Direitos de personalidade.

O Supremo Tribunal de Justiça voltou a acolher a pretensão indemnizatória da autora, mas atribuiu o valor de $€$ I 5.000,00 (quinze mil euros). No entendimento do Supremo Tribunal de Justiça, os danos com mais impacto tinham-se produzido logo no início, portanto, a dada altura, ela estaria à espera de que o relacionamento voltasse a ser o que era, ou seja, houve uma quebra na expectativa de vida em comum da autora. O Supremo Tribunal de Justiça entendeu também que o art. $1.792^{\circ}$ do Código Civil permite a indemnização e não faz distinção do tipo de danos.

O Acórdão foi no sentido de afirmar que foram violados os deveres de fidelidade e de coabitação, mas simultaneamente foram também violados direitos de personalidade, o direito à dignidade pessoal e o direito à saúde.

Para o Tribunal, não é suficiente a simples invocação do direito geral de personalidade, antes deve-se ter bem especificado quais os direitos foram efetivamente violados.

Quanto à saúde da requerente, ficou provado que a senhora sofreu danos na saúde; contudo, não é suficiente existir um dano de certo tipo, visto que não se pode concluir automaticamente pela violação do direito à saúde, ou da prática de um ilícito, pois, afinal, toda pessoa é passível de simplesmente adoecer. Para configuração de um ato ilícito de violação do direito à saúde, teria de existir, por exemplo (ou ao menos restar provada), a incidência de violência doméstica, uma vez que o próprio comportamento é tipicamente apto a provocar dano no direito à saúde.

De qualquer modo, havia o entendimento de que poderia existir um pedido indemnizatório por quaisquer danos, em ação própria, que não na ação do divórcio.

Depois de 2008, com o surgimento do art. $1.792^{\circ}$ do Código Civil, o n I do artigo preconiza o direito à indemnização. $O$ texto da lei expressamente admite que possa haver um pedido indemnizatório pelos danos sofridos com a dissolução do casamento e também com os danos sofridos pela violação de direitos durante o casamento.

No que tange à questão de saber quais são os danos, se acaso são danos ressarcíveis os que atingem direitos da personalidade ou também danos causados por conta da violação dos deveres conjugais, na exposição da aula no curso de Jurisprudência 
ministrada pelo professor doutor Francisco Manuel de Brito Pereira Coelho, este afirmou entender ressarcíveis somente os danos decorrentes da violação dos direitos da personalidade.

O espírito da lei é a de que os cônjuges não fiquem desprotegidos pelo facto de casarem. As pessoas mantêm íntegros os seus direitos de personalidade.

Merece atenção o elemento gramatical da expressão: "nos termos gerais da responsabilidade civil", ou seja, o cônjuge tem direito a pedir a indemnização contratual ou extracontratual. Um exemplo é o caso de a mulher entrar em depressão porque o marido resolveu mudar de partido político. Aqui há um dano à saúde, mas não há um ato ilícito de violação do direito à saúde.

\subsection{A prova do dano extrapatrimonial e o Quantum Indemnizatório}

No caso descrito no Acórdão, não se teve como provado que a autora da ação sofresse de ansiedade e depressão, nem que houvesse sofrido um agravamento do quadro depressivo. Também da factualidade dada como não provada, questões relativas acerca de terem sido realizadas tentativas de estabilização terapêutica e psicotrópica sem sucesso, ou efeitos secundários dos medicamentos. Igualmente não fora provado que ela sofresse de reações emocionais e pensamentos desagradáveis ou que tivesse grandes alterações do ritmo do sono corrigidos à base de medicação. Daí que, ao questionar o alcance de tais expressões, o tribunal da la Instância considerou que a autora prescindiu das provas, uma vez que os laudos médicos apresentados que foram impugnados pelo réu, não puderam ser ratificados, já que os signatários destes, apesar de arrolados como testemunhas, não compareceram em julgamento ${ }^{72}$.

A questão poderia ter sido solucionada se efetuada a perícia judiciária, comumente utilizada, por exemplo, na regulação das responsabilidades parentais, como explica Paula Casaleiro, que "para além das perícias judiciárias que resultam de investigação desenvolvida especialmente para o processo (relatórios sociais, relatórios sociais internacionais, avaliações psicológicas e psiquiátricas e avaliações às competências parentais), a amostra inclui perícias judiciárias que resultam de uma investigação ou exame efetuado noutro contexto, que pode ter relevância para o processo e é solicitada pelo/a magistrado/a, no âmbito da sua liberdade de recolher informações"73.

Entretanto, há um novo questionamento quanto à validade da perícia e à possibilidade de subsunção do entendimento do Juízo a uma perícia realizada por um

72 Acórdão do STJ de 12 de maio de 2016 Relator Tomé Gomes - 2325/I2.3TVLSB.LI.SI, in <http://www.dgsi.pt/jstj.nsf/954f0ce6ad9dd8b980256b5f003fa8l4/c56c09el3e9d3e7e80257fb l 004efl d5? OpenDocument>, Acesso em: 25/7/2019.

73 Paula Casaleiro, A regulação do exercício da regulação das responsabilidades parentais na ponte entre o Direito e outros saberes, in Direito de Família - Vária, Lisboa, Centro de Estudos Judiciários, (2018), p. 63 e ss. 
médico que não acompanhou a evolução do quadro da requerente, em virtude da singularização do tratamento das doenças psicológicas, porque, nas palavras de Paula Casaleiro, "as perícias judiciárias que são convocadas para dizer a 'verdade', oferecem uma leitura da realidade que tende a condicionar a aplicação do direito"74.

A verdade pericial é então elevada quase à posição dominante antes pertencente somente ao Direito, já que recorrer às perícias pode ser compreendido como uma mudança dos fundamentos e dos modos de ação da instituição judiciária, que se vê, de certo modo, condicionada, colocando os magistrados "numa posição não mais de decisor, mas sobretudo de 'supervisor', ou seja, de instância de legitimação das decisões preestabelecidas pela perícia"75.

Embora observável esse processo de transformação e ainda que ausente perícia judiciária e depoimento dos signatários dos laudos apresentados pela requerente, o Tribunal, na revista, manteve como factualidade provada que o estado mental da autora é devido ao relacionamento conjugal. Assim, o papel dos profissionais da magistratura foi ratificado sem deixar de ter em conta o poder-dever precípuo do Tribunal na proteção dos cônjuges.

O acórdão diz que "no que respeita à substituição do termo depressivo empregue no ponto I 4 da sentença pelo vocábulo mental, uma vez que este qualificativo tem uma denotação mais vincada com o estado clínico patológico dado como não provado, tem-se por correta a substituição operada no acórdão recorrido, por ser mais neutra, estando, como está, substancialmente, conexionada com o ponto $12 .^{\circ}$ dos factos provados. De resto, trata-se de um termo que não visa, por si, caracterizar o estado psíquico da A., mas apenas mencionar, genericamente, o constante do ponto 1 . I 2 da factualidade acima descrita, de modo a conectá-lo com o relacionamento conjugal"76.

Assim, parece ser o caso de atentar às lições de Giuseppe Cassano e Giacomo Oberto, já que relativamente à prova, a palavra-chave acerca da existência do próprio dano parece ser concreta. Dito de outro modo, para os autores, aquele que alega ser ferido em seu âmbito inviolável terá de provar que foi efetivamente em virtude do comportamento ilícito de outrem.

A concretude da prova que se persegue, é a de que esta seja dotada de apreciação objetiva, verificável, mesmo presumivelmente, no campo da realidade atual segundo dados da experiência comum, e não deixado ao simples capricho daqueles

74 Paula Casaleiro, A regulação do exercício da regulação das responsabilidades parentais na ponte entre o Direito e outros saberes, ob. cit., p. 63 e ss.

75 Paula Casaleiro, A regulação do exercício da regulação das responsabilidades parentais na ponte entre o Direito e outros saberes, ob. cit. p. 63 e ss.

76 Acórdão do STJ de 12 de maio de 2016 Relator Tomé Gomes - 2325/I2.3TVLSB.LI.SI, in <http://www.dgsi.pt/jstj.nsf/954f0ce6ad9dd8b980256b5f003fa8/4/c56c09el3e9d3e7e80257fb l 004efl d5? OpenDocument>, Acesso em: 26/7/2019. 
que se consideram destinatários do direito. As gradações em termos de oferta de prova de dano podem variar dependendo da situação que está sendo examinada pelo juiz ${ }^{77}$.

Superadas as questões acerca da prova do dano, é imprescindível a discussão a respeito de outro assunto de extrema relevância na demanda que provocou o acórdão: o quantum a ser fixado.

Logo de início, é importante considerar que a reparação, na qual se convertem em pecúnia os danos extrapatrimoniais, deve ter caráter compensatório, para que o ofendido, recebendo determinada soma pecuniária, possa amenizar os efeitos decorrentes do ato de que foi vítima.

Nesse sentido, para o presente trabalho, o valor da indenização deve ser substancial, pois do contrário não estaria a cumprir o seu papel de compensar adequadamente a ofendida. Ante esse raciocínio, devem-se sopesar, no caso concreto, todas as circunstâncias que possam influenciar na fixação do quantum indemnizatório, levando em consideração que o dano extrapatrimonial abrange, além das perdas valorativas internas, as exteriorizadas no relacionamento diário pessoal, familiar, profissional e social da ofendida.

Por outro ângulo, a indemnização por danos extrapatrimoniais deve ser fixada de maneira que a condenação atinja efetivamente, de modo significativo, o patrimônio do causador do dano.

Embora não se tenham parâmetros rígidos para encontrar o valor real da indenização, existe orientação no sentido de que não deve a importância ser ínfima, de forma a não valorizar o dano extrapatrimonial, nem tão elevada que cause enriquecimento indevido ao ofendido.

Ou seja, na fixação da indenização devem ser consideradas as condições econômicas das partes, as circunstâncias em que ocorreu o fato, o grau de culpa do ofensor, a intensidade do sofrimento, propiciando à vítima satisfação, com o cuidado para não se constituir em meio de enriquecimento indevido. Em suma, está a reparação do dano extrapatrimonial conjugada à satisfação do ofendido e deverá sempre ser aplicada de acordo com o princípio da razoabilidade.

Tal foi o entendimento do Superior Tribunal de Justiça. Contudo, sobre a efetiva reparação do dano, o Tribunal decidiu timidamente ao reduzir o valor para a quantia de quinze mil euros, visto que, no caso em tela, o direito ao ressarcimento da autora, via indemnização por danos extrapatrimoniais, pelo descaso e desatenção do réu, consubstanciados nas práticas supra descritas, causou não só um estado permanente de ansiedade e depressão, mas também de infelicidade.

77 Giuseppe Cassano, Giacomo Oberto, (et al.), La famiglia in crisi: invalidità, separazione e divorzio dopo le riforme, come si quantificano i profili patrimoniali, quali le conseguenze personali e le relative tutele, Milano, Wolters Kluwer, CEDAM, 2016, p. 49. 
O réu fez uma opção quando saiu do ambiente conjugal pela primeira vez. Porém, das lições de Pedro Pais de Vasconcelos, aprende-se que "a dignidade originária e fundamental da pessoa e as suas consequentes liberdade e autonomia só se podem articular coerentemente com a responsabilidade da pessoa pelas suas ações"78.

Ora, se "a liberdade e autonomia da pessoa tem como correspondentes a responsabilidade civil e criminal"79, e, no que tange ao princípio da responsabilidade, a responsabilidade civil está restrita aos atos ilícitos livres e culposos, não se trata, portanto, de mero dissabor nem de mero aborrecimento, que dependessem exclusivamente de a autora decidir pelo divórcio ${ }^{80}$.

O caso em comento era apto a ensejar a reparação indemnizatória realmente eficaz, de maneira que, acerca do estabelecimento do valor efetivo a pagar, a jurisprudência do Tribunal, ao menos no presente caso, mostrou-se por demasiado casmurra.

\section{CONCLUSÃO}

Em análise ao Acórdão do Supremo Tribunal de Justiça, de 12/5/2016, Proc.2325/I2.3TVLSB.LI.SI, entendeu-se que foram violados os deveres de fidelidade e de coabitação, mas, simultaneamente, foram também violados direitos de personalidade, o direito à dignidade pessoal e o direito à saúde.

O texto do art. $1.792^{\circ}$ do Código Civil, $n^{\circ}$ I, preconiza expressamente o direito à indemnização. A norma admite que é cabível o pedido indemnizatório pelos danos sofridos com a dissolução do casamento e também com os danos sofridos pela violação dos direitos conjugais durante o casamento.

A conclusão é a de que, relativamente ao tipo de dano, são ressarcíveis os danos decorrentes de violações ao Direito de personalidade, bem como os danos por con-

78 Pedro Pais de Vasconcelos, Teoria Geral do Direito Civil Relatório, Revista da Faculdade de Direito da Universidade de Lisboa, Lisboa, Coimbra Editora, 2000, p. 61.

79 Idem.

80 Pelos limites do trabalho, a opção foi no sentido de prescindir maiores explanações acerca da função ressarcitória da indemnização e também acerca das causas justificativas do facto danoso. Entretanto, apenas ad argumentandum tantum, informa que cabe reflexão a respeito do comportamento da autora da ação no sentido de que o consentimento do lesado é uma causa justificativa, que retira ao fato que ocasionou o dano a sua ilicitude nos termos do art. $340^{\circ}, n^{\circ}$ I e 2, no qual o "ato lesivo dos direitos de outrem é lícito, desde que o ofendido consinta na lesão", e o n 3 do art. $340^{\circ}$ quanto à presunção de consentimento. (cfr. MÁrIO JúLIO DE ALMEIDA Costa, Direito das Obrigações, $12^{a}$ Ed. Revista e Atualizada, Coimbra, Almedina Editora, 2016, p. 576.). Também não se avalia se o comportamento inerte da autora serviu como uma exteriorização do consentimento, uma vez que poderia exercer sua vontade e requerer o divórcio no início. Todavia não se perde de vista que possam existir casos em que os indivíduos proponham ações meramente argentárias de exclusivo interesse patrimonial. 
ta da violação dos deveres conjugais, como corolário lógico do dever de proteção que abrange o Direito da Família.

Especificamente, relativo ao quantum indemnizatório, não se trata de atribuir valor pecuniário ao amor, mas a reparação pretendida pela responsabilização civil deve objetivamente compensar o lesado.

A relação conjugal é um comportamento essencialmente volitivo. Ao individuo é salvaguardada a liberdade de amar, de ser amado ou deixar de amar. Todavia, se houver violação de direitos e de bens jurídicos tutelados, é justo ao componente da entidade familiar lesado buscar a reparação ou a compensação dos danos sofridos, mesmo que a violação tenha ocorrido ao abrigo da conjugalidade.

\section{REFERÊNCIAS}

AAW. Indemnização das vítimas de crimes, in <https://e-justice.europa.eu/home. do? lang=pt\&action $=$ home $>$, Acesso em: 19/7/2019

AAW. Violência Doméstica - Implicações sociológicas, psicológicas e jurídicas do fenómeno - Manual Pluridisciplinar, Caderno Especial, Centro de Estudos Judiciários, Lisboa, (2016).

Albengo, Paolo Giovanni Demarchi (et al.) - Famiglia Trattario di diritto civile, Milano: Giuffrè Editore, 20।4. XXIX, 895 p.

Bianca, Cesare Massimo - La riforma della filiazione, Assago: Wolters Kluwer, 2015.

BLOGUe LITERÁRIO BeRTRAND. Um amor para vida toda, in <https://bertrandptsomoslivros. blog/20 19/02/0 I/um-amor-para-toda-a-vida-romeu-e-julieta/>, Acesso em: 10/8/2019.

CAnotilho, J.J. Gomes - Direito Constitucional e a Teoria da Constituição, $7^{a}$ Ed, Coimbra : Editora Almedina, 2003.

CASAleiro, PAULA - A regulação do exercício da regulação das responsabilidades parentais na ponte entre o Direito e outros saberes, in Direito de Família - Vária, Lisboa, Centro de Estudos Judiciários, (2018), p. 63 e ss.

CASSANO, GIUSEPPE, OBERTO, GIACOMO, (et al.) - La famiglia in crisi: invalidità, separazione e divorzio dopo le riforme, come si quantificano i profili patrimoniali, quali le conseguenze personali e le relative tutele, Milano : Wolters Kluwer: CEDAM, 2016.

Cendon, PaOlo - Trattario di Diritto Civile Famiglia, Milano: Giuffré Editore, 2014.

Coelho, Francisco Pereira, Oliveira, Guilherme - Curso de Direito da Família, Volume I, Coimbra : Coimbra Editora, 2016. 
DOR DE AMOR OU DANOS DE AMOR? JURISPRUDÊNCIA RENITENTE: O PROBLEMA DO QUANTUM INDEMNIZATÓRIO DA RESPONSABILIZAÇÃO CIVIL NO PLANO DAS RELAÇÕES CONJUGAIS

Cordeiro, António Menezes - Tratado do Direito Civil Português I, 4ª Ed., Coimbra : Almedina Editora, 2012.

Costa, Mário Júlıo de Almeida - Direito das Obrigações, I $2^{a}$ Ed. Revista e Actualizada, Coimbra : Almedina Editora, 2016.

Damião, Regina Toledo, Henriques, Antônio - Curso de Português Jurídico, $10^{a}$ ed., São Paulo : Editora Atlas, 2009.

Diana, Daniela, Romeu e Julieta. Resumo de livros, in <https://www.todamateria. com.br/romeu-e-julieta/> Acesso em: 17/7/2019.

Dias, Maria Berenice - Filhos do afeto, $2^{a}$ Ed., São Paulo : Editora Revista dos Tribunais, 2017.

Dias, Maria Berenice - Manual de Direito das Famílias, $9^{a}$ ed., São Paulo : Editora Thomson Reuters Revista dos Tribunais, 2015.

Dias, Maria Berenice, Casamento ou terrorismo sexual, in < http://www.mariaberenice. com.br> Acesso em: 19/7/2019.

Dias, Maria Berenice, Casamento: nem direitos nem deveres, só afeto, in < http://www. mariaberenice.com.br> Acesso em: 19/7/2019.

Dias, Maria Berenice, Estatização do afeto, in < http://www.mariaberenice.com.br> Acesso em 19/07/2019

Exposição de Motivos da Lei no 509/X, in <https://www.parlamento.pt/ ActividadeParlamentar/Paginas/Detalhelniciativa.aspx?BID=33847>, Acesso em: $17 / 7 / 2019$

Farias, Cristiano Chaves de - (et al.) Tratado de direito das famílias, 2a ed. Belo Horizonte: Instituto Brasileiro de Direito de Família, 2016.

Fialho, António José - Guia Prático do Divórcio e das Responsabilidades Parentais, $2^{\mathrm{a}}$ Edição, Lisboa: CEJ, 2013.

HAUSER, JEAN - Amour et liberté, la divise contemporaine du couple? La famille en mutation. Archives de Philosophie du Droit. Paris: Dalloz. Tome 57, (20।4), p. 73 e ss.

Hörster, Heinrich Ewald - A Parte Geral do Código Civil Português, Teoria Geral Do Direito Civil, Coimbra : Editora Almedina, 2007.

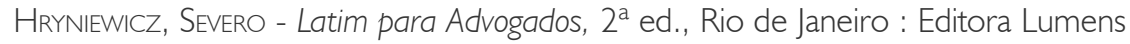
Juris, 2005. 
JoRGE, NUNO Lemos - As providências especiais previstas no artigo $931^{\circ} \mathrm{n}^{\circ} 7$, do Código de Processo Civil - Natureza e Procedimentos, in Direito de Família - Vária, Lisboa, Centro de Estudos Judiciários, (2018), p. 39 e ss.

Multedo, Renata VILELA - Liberdade e família - Limites para a intervenção do Estado nas relações conjugais e parentais, Rio de Janeiro : Editora Processo, 2017.

PASSINHAS, SANDRA - O novo paradigma do divórcio em Portugal - Ainda há deveres no casamento? AAW. O Divórcio, Lisboa, Centro de Estudos Judiciários, (20।4), p. 34 ess.

Pereira, Rodrigo da Cunha Pereira - Princípios fundamentais norteadores do direito de família, $3^{\mathrm{a}}$ ed. São Paulo : Editora Saraiva, 2016.

PinheIRo, Jorge DuARTE - O Direito da Família Contemporâneo, $4^{\mathrm{a}}$ Ed., Lisboa, AAFDL Editora, 2015.

Rodotá, Stefano - Diritto d'amore, Bari, Laterza, 2015, in <https://www. libreriauniversitaria.it/diritto-amore-rodota-stefano-laterza/libro/9788858|2 |245> e $<$ https://books.google.pt/books >, acesso em: 10/8/2019.

Varela, Antunes - Das Obrigações em Geral, Vol. I, I $0^{a}$ Ed., Coimbra : Ed. Almedina, 2000.

Vasconcelos, Pedro Pais de - Teoria Geral do Direito Civil Relatório, Revista da Faculdade de Direito da Universidade de Lisboa, Lisboa: Coimbra Editora, 2000.

Violência Doméstica - Implicações sociológicas, psicológicas e jurídicas do fenómeno - Manual Pluridisciplinar.

Vítor, PAULA TÁVORA, Les implicites des techniques de règlemente des comptes dans les coupes séparés: les obligations alimentaires entre ex-époux, in Lex Familiae, Revista de Direito Portuguesa, Centro de Direito da Família, Coimbra Editora, Ano 14 - n. ${ }^{\circ} 27-28,(2017)$, p. 137 e ss.

Waquim, BRUNa BARBIERI - Universos paralelos e danos de amor: balizas para a responsabilidade civil no âmbito das relações simultâneas conjugais, in Revista Brasileira de Direito das Famílias e Sucessões. A. 13, n 23 (ago./set. 20I I), p. 65-83.

\section{Páginas da Internet Acedidas:}

http://www.cej.mj.pt

http://www.dgsi.pt 
DOR DE AMOR OU DANOS DE AMOR? JURISPRUDÊNCIA RENITENTE: O PROBLEMA DO QUANTUM INDEMNIZATÓRIO DA RESPONSABILIZAÇÃO CIVIL NO PLANO DAS RELAÇÕES CONJUGAIS

http://www.mariaberenice.com.br

http://www.planalto.gov.br/ccivil_03/LEIS/2002/L I 0406.htm

http://www.senato.it

https://www.dirittoprivatoinrete.it/la_parentela_e_laffinita.htm

https://www.legifrance.gouv.fr

https://www.parlamento.pt/Legislacao

https://www.todamateria.com.br

Recebido em: 18/08/2019

Aprovado em: 25/08/2019 
